\section{Bilateral cavernous sinus thrombosis as first manifestation of primary Burkitt lymphoma of the thyroid gland}

\section{Mehdi Moghaddasi, Mona Nabovvati, Saeed Razmeh}

Department of Neurology, Iran University of Medical Sciences, Tehran, Iran

\begin{abstract}
Cavernous sinus thrombosis (CST) is a rare condition that is usually associated with infections, pregnancy, vasculitis and some types of medication, such as the contraceptive pill and paraneoplastic. Primary Burkitt lymphoma (PBL) of the thyroid gland is very uncommon and the clinical description of such cases has been largely limited to case reports. In this paper, we present a case of CST as the first manifestation of PBL of the thyroid gland. To the best of our knowledge, our patient is the first case report of PBL of the thyroid gland that presents with bilateral CST.
\end{abstract}

\section{Introduction}

Cavernous sinus thrombosis (CST) is a rare condition that usually due to infections, pregnancy, vasculitis and some types of medication, such as contraceptive pill. ${ }^{1}$ Burkitt lymphoma is a form of nonHodgkin's lymphoma that starts in immune cells called B-cells and is highly aggressive and fatal without treatment. ${ }^{2}$ Primary Burkitt lymphoma (PBL) of the thyroid gland is a very uncommon and the clinical description of such cases has been largely limited to case reports. The early clinical effects of PBL of the thyroid gland are dyspnea, dysphagia, pain and hoarseness of voice that might be due to compression effects of tumor and lymphadenopathy. The early manifestation of this tumor with CST is very rare.3,4 This report describes a 34 year-old woman who had the CST as the initial manifestation of Primary Burkitt lymphoma of the thyroid gland.

\section{Case Report}

A 47-year-old Iranian women was referred to our hospital with diplopia. The early Symptoms had begun 1 months earlier with binocular diplopia, headache and nausea. A headache was bifrontal, pulsatile and exacerbated by supine position. Previous medical history was unremarkable. There is no family history of heart disease, liver cancer and stroke. On examination, he was conscious and had stable vital signs, there was no peripheral lymphadenopathy palpable. He had normal rate and regular rhythm, no murmur. Abdomen was flat, soft and non-tender with normal liver and spleen. Extremities had normal findings. Neurological examination shows complete ophthalmoplegia of left eye and sensory loss of the first and second division of the left trigeminal nerve. Muscle strength was $5 / 5$ in all four limbs. All deep tendon reflexes were normal and plantar response was bilateral flexor. On 3 day of admission, she experienced a diplopia and a left ptosis in other eye. On MR (Figure 1), there was symmetrical enlargement of both cavernous sinuses that enhanced after contrast. After the anticoagulation therapy with enoxaparin and warfarin, in follow up MRI, complete improvement was seen. The laboratory studies, including complete blood count, creatine kinase, erythrocyte sedimentation rate, and C-reactive protein level were normal. The thyroid function tests, anti-thyroglobulin and thyroid-stimulating hormone receptor antibody also were normal. Cerebrospinal fluid (CSF) was normal in cell count, protein, glucose and cytology. The work up for occult malignancy including chest $\mathrm{CT}$, abdominopelvic CT, and mammography was normal, the PET scan was not done but Due to the neck pain that developed in the course of hospitalizations, the neck sonography was done that showed enlargement of thyroid gland with lymphadenopathy. The surgical biopsy was done for the patient and PBL of thyroid finally was diagnosed. The bone marrow also biopsy was done that was negative. The chemotherapy was started for her in ward chemotherapy but she succumbed 1 month after the diagnosis due to lack of response to the treatment and upper respiratory tract involvement.

\section{Discussion}

Primary thyroid lymphoma (PTL) is a rare thyroid malignancy that accounts for about 1 to $5 \%$ of all thyroid cancers and $2 \%$ of all malignant extra nodal lymphomas. It is found more in older patients and has predominance in women and is usually associated with Hashimoto thyroiditis. 5 The common subtypes are diffuse large B cell lymphoma, mucosa-associated lymphoid tissue
Correspondence: Saeed Razmeh, Department of Neurology, Iran University of Medical Sciences, Corner of First St., Hijab St., Keshavarz Blvd., Tehran, Iran.

Email:srazmeh@yahoo.com

Key words: Cavernous sinus thrombosis; Primary Burkitt lymphoma; Thyroid gland.

Received for publication: 14 March 2017 Revision received: 19 April 2017.

Accepted for publication: 27 May 2017

This work is licensed under a Creative Commons Attribution NonCommercial 4.0 License (CC BY-NC 4.0).

(C) Copyright M. Moghaddasi et al., 2017

Licensee PAGEPress, Italy

Neurology International 2017; 9:7133

doi:10.4081/ni.2017.7133

(MALT) lymphoma and primary Burkitt lymphoma. ${ }^{6}$ Burkitt lymphoma of the thyroid gland are very rare and has been largely limited to case reports. In study by Campagno et al. retrospectively reviewed 245 patients with lymphoma of the thyroid gland, Burkitt's lymphoma was observed in $3(1.2 \%)$ of patients. ${ }^{7}$ Clinically, PBL like anaplastic thyroid carcinoma has rapid grow with compression symptoms consisted dyspnea, dysphagia, pain, hoarseness of voice and lymphadenopathy. Paraneoplastic neurological syndromes (PNSs) rarely associate with lymphoma. They include cerebellar degeneration, dermato/polymyositis, sensory neuronopathy, Lambert- Eaton myasthenic syndrome, granulomatous angiitis, cerebrovascular disease, subacute necrotizing myelopathy and encephalomyelitis. 8,9 Cavernous sinus thrombosis (CST) as an initial presentation of lymphoma, especially thyroid Burkitt lymphoma is very rare. To the best of our knowledge, our patient is the first case report that CST present as first manifestation of PBL of thyroid. The clinical effects of CST are headache, diplopia, proptosis, impaired visual acuity and ophthalmoplegia due to involvement of cranial nerves, optic nerve and venous drainage that are located within or along the cavernous sinus. ${ }^{10-12} \mathrm{CT}$ and MR provide useful information to the diagnosis and exclude other pathology that can mimic this sign and symptoms. ${ }^{13}$ In our patient on MRI, there was asymmetrical cavernous sinus enhancement. In differential diagnosis, in addition to CST, Carcinomatous meningitis also should be considered. But due to, in the course of disease that we was seen the complete improvement in follow up MRI, before the onset of chemotherapy and after anticoagu- 

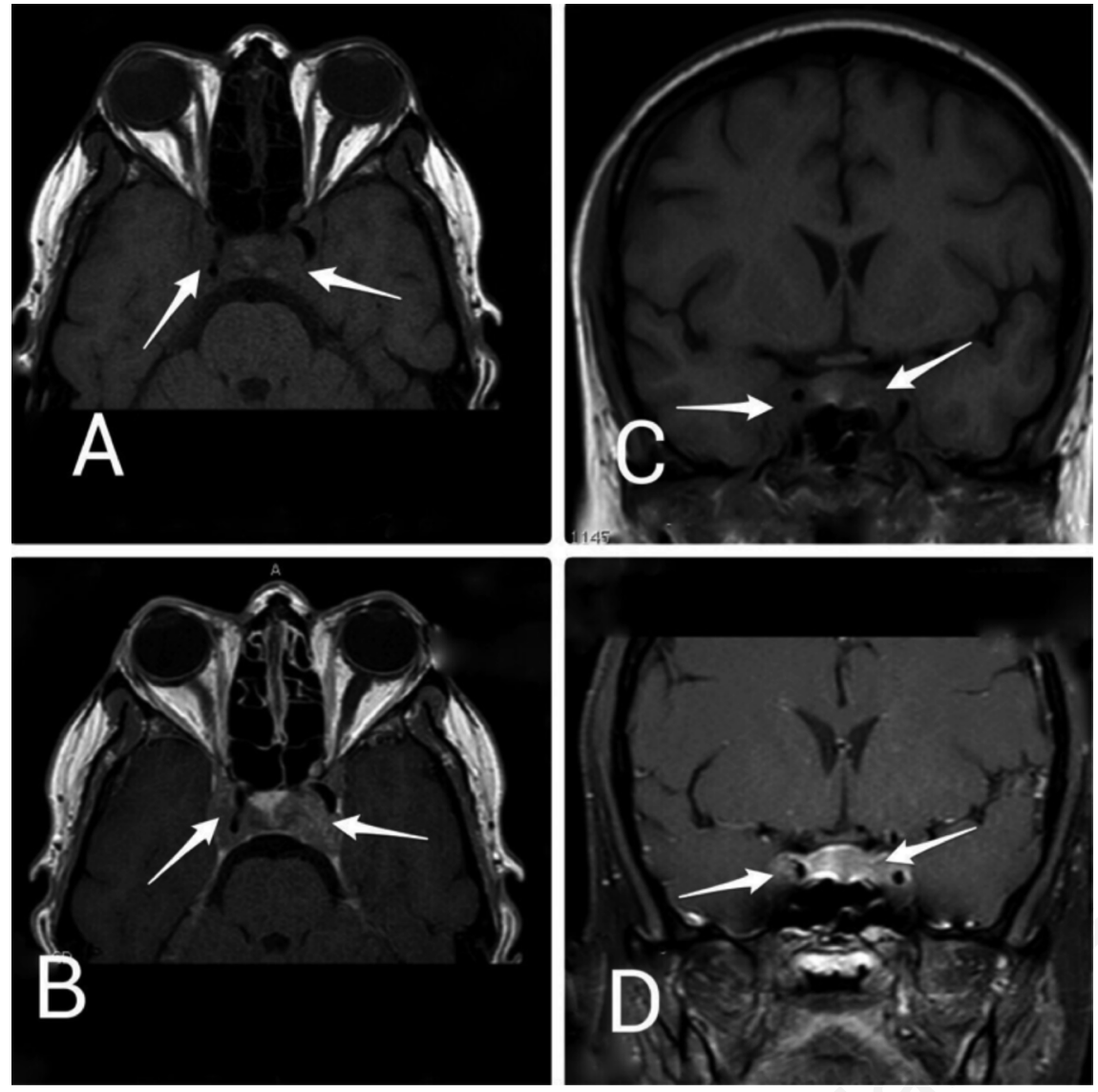

Figure 1. Axial and coronal T1 weighted images (A and C) show bilateral asymmetrical enlargement of cavernous sinuses with inhomogeneous contrast enhancement (B and D).

lant therapy and normal CSF cytology, the diagnosis of CST is more likely in the presence of this clinical features. For diagnosis of thyroid Burkitt lymphoma, core needle biopsy has higher sensitivity and positive predictive value than FNA for the diagnosis of thyroid gland lymphomas because the presence of concurrent Hashimoto thyroiditis, decrease the accuracy of FNA.14,15 In our patient at first FNA was done for the patient that the Hashimoto thyroiditis was diagnosed but after surgical biopsy, Burkitt lymphoma diagnosed. The first step in treating is to eliminate the underlying cause to reduce the risk of recurrence, but due to prevent further thrombosis, anticoagulation with heparin should be considered. ${ }^{16,17}$ In our case heparin and chemotherapy were started but she succumbed one month after the diagnosis of the disease.

\section{Conclusions}

In conclusion, paraneoplastic bilateral
CST as the first presentation of lymphoma is very unusual. But in any case without evidence of common causes, hypercoagulability state and malignancy should be considered.

\section{References}

1. Ceyhan P, Erdem G, Kanra G, et al. Lymphoma with bilateral cavernous sinus involvement in early childhood. Pediatr Neurol 1994;10:67-69.

2. Spina M, Tirelli U, Zagonel V, et al. Burkitt's lymphoma in adults with and without human immunodeficiency virus infection. Cancer 1998;82:766-74.

3. Kalinyak JE, Kong CS, McDougall IR. Burkitt's lymphoma presenting as a rapidly growing thyroid mass. Thyroid 2006;16:1053-7. Frommelt RA, et al. Malignant lymphoma of the thyroid gland: a clinicopathologic study of 108 cases. Am J
4. Derringer GA, Thompson LD,
Surg Pathol 2000;24:623-39.

5. Pedersen RK, Pedersen NT. Primary non-Hodgkin's lymphoma of the thyroid gland: a population-based study. Histopathology 1996;28:25-32.

6. Ha CS, Shadle KM, Medeiros LJ, et al. Localized non-Hodgkin lymphoma involving the thyroid gland. Cancer 2001;91:629-35.

7. Compagno J, Oertel JE. Malignant lymphoma and other lymphoproliferative disorders of the thyroid gland. A clinicopathologic study of 245 cases. Am J Clin Pathol 1980;74:1-11.

8. Yildiz I, Sen F, Toz B, et al. Primary Burkitt's lymphoma presenting as a rapidly growing thyroid mass. Case Rep Oncol 2012;5:388-93.

9. Albert S. Primary Burkitt lymphoma of the thyroid. Ear Nose Throat J 2013;92:e1-2.

10. Lam KY, Lo CY, Kwong DL, et al. Malignant lymphoma of the thyroid. A 30-year clinicopathologic experience and an evaluation of the presence of Epstein-Barr virus. Am J Clin Pathol 1999;112:263-70.

11. Kalinyak JE, Kong CS, McDougall IR, et al. Burkitt's lymphoma presenting as a rapidly growing thyroid mass. Thyroid 2006;16:1053-7.

12. Delpassand ES, Kirkpatrick JB. Cavernous sinus syndrome as the presentation of malignant lymphoma. Neurosurgery 1988;23:501-4.

13. Cakirer S. MRI findings in the patients with the presumptive clinical diagnosis of Tolosa Hunt syndrome. Eur Radiol 2003;13:17-28.

14. Stein SA, Wartofsky L. Primary thyroid lymphoma: a clinical review. J Clin Endocrinal Metab 2013;98:3131-8.

15. Allaoui M, Benchafai I, Mahtat el M, et al. Primary Burkitt lymphoma of the thyroid gland: case report of an exceptional type of thyroid neoplasm and review of the literature. BMC Clin Pathol 2016;16:6.

16. Dunleavy K, Pittaluga S, Shovlin M, et al. Low-intensity therapy in adults with Burkitt's lymphoma. N Engl J Med 2013;369:1915-25.

17. Hernández JA, Reth P, Ballestar E, et al. Primary thyroid lymphoma with bone marrow and central nervous system infiltration at presentation. Med Clin (Barc) 2001;116:357-8. 